NASA Technical Memorandum 105971

AIAA-93-0031

\title{
Surface Roughness Due to Residual Ice in the Use of Low Power Deicing Systems
}

Jaiwon Shin and Thomas H. Bond

Lewis Research Center

Cleveland, Ohio

Prepared for the

31st Aerospace Sciences Meeting \& Exhibit

sponsored by the American Institute of Aeronautics and Astronautics

Reno, Nevada, January 11-14, 1993 


\title{
SURFACE ROUGHNESS DUE TO RESIDUAL ICE IN THE USE OF LOW POWER DEICING SYSTEMS
}

\author{
Jaiwon Shin* \\ Thomas H. Bond* \\ NASA Lewis Research Center \\ Cleveland, Ohio
}

\section{$\underline{\text { Abstract }}$}

Thicknesses of residual ice are presented to provide information on surface contamination and associated roughness during deicing events. Data was obtained from low power ice protection systems tests conducted in the Icing Research Tunnel at NASA Lewis Research Center (LeRC) with nine different deicing systems. Results show that roughness associated with residual ice is not characterized by uniformly distributed roughness. Results also show that deicing systems require a critical mass of ice to generate a sufficient expelling force to remove the ice.

\section{Introduction}

With the advent of the increased use of turbofan engines on modern aircraft, the engine core flow has decreased substantially, causing concern about the operation of engine bleed air equipment, i.e., hot bleed air anti-icing systems. The high cost, in terms of electrical power and weight, has always been an issue in restricting the application of electrically heated (thermal) anti-icers. Advances in new low power ice protection designs may provide opportunities to overcome the above limitations.

Unlike conventional anti-icing systems, deicing systems let ice accrete on the surface until there is enough mass to expel. Most of the new deicing technologies rely on very rapid surface displacement, induced by a repulsive force, to crack and debond the ice. Once expelled, the shed ice particles are carried away from the surface by the airflow. With this ice protection technology approach, the surface becomes contaminated with the initial ice buildup and may remain contaminated with residual ice after deicer activation.

Effects of wing contamination by ice and frost have been studied using either discrete or distributed roughness to simulate ice and frost [1-5]. Brumby [1] correlated various test data of lift loss due to discrete wing surface roughness representing a Reynolds number ranging from $6 \times 10^{5}$ up to $29 \times 10^{6}$ and airfoil shapes ranging from simple symmetrical sections to those representative of second-generation aircraft. This empirical correlation showed a significant loss of $\mathrm{C}_{1, \max }$ due to surface roughness. Recently, Lynch, et al. [2] tested effects of very small leading edge ice simulated by distributed roughness on a multielement high-lift airfoil for both single and multi-element configurations. Their results indicated much higher loss in maximum lift than predictions by Brumby's correlation. Results from other work [3-5] all indicated severe losses in maximum lift due to the leading edge roughness. Regardless of differences in severity, results from the work cited above showed that the most predominant adverse effect of the leading edge roughness is on the lifting characteristics of wings. Since deicing systems allow an initial ice buildup and may leave residual ice, surface contamination due to residual ice is of great concern with respect to wing aerodynamics.

\footnotetext{
* Aerospace Engineer, Member AIAA

Copyright (C) 1993 by the American Institute of Aeronautics and Astronautics, Inc. No copyright is asserted in the United States under Title 17, U.S. Code. The U.S. Government has a royalty-free license to exercise all rights under the copyright claimed herein for Governmental purposes.

All other rights are reserved by the copyright owner.
} 
The USAF and NASA conducted two tests with low power deicing systems in the NASA Lewis Icing Research Tunnel (IRT): one in 1990 and another in 1991 [6,7]. Eight deicing systems in 1990 and two systems in 1991 were tested through a range of icing spray times and cycling rates at both glaze and rime icing conditions. The main objective of the tests was to assess the current state-ofthe-art of low power deicing technologies. To achieve the main objective, shed ice particle size, residual ice, and power usage were documented. In this paper, the thickness of residual ice measured during the tests is presented in order to provide information on surface roughness associated with residual ice.

\section{Hardware and System Description}

\section{Icing Research Tunnel}

The NASA LeRC IRT is a closed-loop refrigerated wind tunnel. A $5000 \mathrm{hp}$ fan provides airspeeds up to $134 \mathrm{~m} / \mathrm{sec}(300$ $\mathrm{mph})$. The refrigeration heat exchanger can control the total temperature from - 1.1 to $-42{ }^{\circ} \mathrm{C}$. The spray nozzles provide droplet sizes from approximately 10 to $40 \mu \mathrm{m}$ median volume droplet diameters (MVD) with liquid water contents (LWC) ranging from 0.2 to $3.0 \mathrm{~g} / \mathrm{m}^{3}$. The test section of

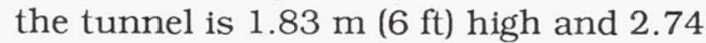
$\mathrm{m}(9 \mathrm{ft})$ wide. Figure 1 shows a plan view of the tunnel and shop area.

\section{$\underline{\text { Test Model }}$}

\section{Test}

To eliminate any geometrysensitive issues in regard to both hardware installation and operation, a generic airfoil with a relatively moderate leading edge radius was

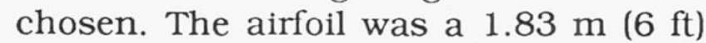
span NACA 0012 airfoil with a $0.53 \mathrm{~m}$ (21 in) chord (Fig. 2). There was a break between the leading and trailing edges at $0.18 \mathrm{~m}$ (7 in) that allowed the front section to be removed. Each participating company installed their deicer on the leading edge section which was joined with the trailing edge. The airfoil was made with a wood spar, foam core, and a fiberglass skin. The model was mounted vertically in the center of the test section and set at a $4^{\circ}$ angle-of-attack for the entire test.

\section{Test}

One of the objectives for this test was to examine effects of geometry on the system performance. The model chosen was a $1.22 \mathrm{~m}$ (4 ft) long, swept engine inlet component which had curved top and bottom ends (Fig. 3). The model also had a varying leading edge radius along the span with a leading edge radius near the top of $6.35 \mathrm{~mm}$ (0.25 in) and a leading edge radius near the bottom of $19.0 \mathrm{~mm}$ (0.75 in). The model was fitted with fairings at both the top and bottom to minimize flow disturbances. The model, with a streamlined afterbody, was mounted vertically in the center of the test section.

\section{Deicing Systems}

\section{Test}

The eight deicers tested can be broadly defined under four different technologies: electro-expulsive, eddy current repulsive, high pressure pneumatic, and low profile conventional pneumatic. The first two technologies require a capacitor bank storage supply to provide the high amperage, short duration current pulse necessary to initiate the repulsive mechanism. The last two use pneumatic pressure to generate the ice debonding process. Manufacturers and system types are listed in Table 1.

The electro-expulsive deicer tested by Dataproducts New England, Inc. was composed of two conductors overlaying each other in an elastomeric blanket. 
High amperage, opposing currents were discharged through the conductors (from a capacitor storage supply) with the resulting magnetic fields producing an electro-expulsive force. This caused the upper conductor to be repelled from the lower one with a high magnitude, short duration force which debonded and expelled the ice accreted to the outer elastomer.

Eddy current repulsive technology (EIDI) was used by a number of companies including systems from Rohr Industries, Inc., Advance Concepts De-Icing Company, Garrett Canada, Electroimpact, Inc., and BFGoodrich De-Icing Systems. There were variations in design and fabrication methods; however, the general repulsive mechanism is the same for all systems. A high amperage electric current pulse is sent through a spirally wound cylindrical coil or flat, pancake coil which is placed either on the inside or the outside of the airfoil skin. This produces a magnetic field which induces an eddy current in the doubler plate attached adjacent to the coil. The two currents' fields repelled each other with a resultant small displacement, high acceleration force that cracks and debonds the ice.

There was one pneumatic-expulsive technology that used high pressure air to initiate the expelling force. This system was the Pneumatic Impulse Ice Protection (PIIP) deicer tested by BFGoodrich De-Icing Systems. The deicer is composed of a matrix of spanwise fabric-reinforced tubes which lay flat in the relaxed state. When the system is activated the rapidly pressurized tubes expand slightly with a resultant distortion of the outer surface that debonds the ice. The high acceleration of the skin due to the extremely fast pressure pulse launches the shattered particles into the airstream.

The final technology tested was a variation on conventional pneumatic deicers, the BFGoodrich De-Icing Systems Small Tube Pneumatic (STP) system. This deicer uses relatively low pressure to inflate a number of spanwise tubes embedded in an elastomer blanket, that subsequently break the ice bonds. The aerodynamic forces from tunnel velocity then help to remove the debonded ice and carry it away. More information on the deicers can be found in Ref. 6 .

\section{Test}

The two deicers tested were the Pneumatic Impulse Ice Protection (PIIP) system and the Electro-Expulsive Deicing System (EEDS), both from BFGoodrich De-Icing Systems. The PIIP system was the same kind as the one tested during the 1990 test; the EEDS used a technology similar to the EEDS of Dataproducts New England, Inc. described in the previous section.

\section{Measurement Device}

A dial indicator gage with a dial which could read down to $25 \mu \mathrm{m}(1 / 1000$ in) was modified for ice thickness measurements (Fig. 4). The bottom plate of the device was placed against high points of the iced surface and the arm would contact a cleared spot on the airfoil surface to give a reading. The device was simple to use and provided readings with good repeatability.

\section{Test Methods}

\section{Test Condition}

For both tests, two cloud conditions were chosen to cover both a glaze ice and rime ice regime. Both reflect ice accretions that have historically been hard to remove.

\section{Test}

The airspeed for the glaze ice condition was $67.1 \mathrm{~m} / \mathrm{s}(150 \mathrm{mph})$ at $-3.9^{\circ} \mathrm{C}\left(25^{\circ} \mathrm{F}\right)$ with $0.55 \mathrm{~g} / \mathrm{m}^{3}$ of LWC, 
and an MVD of $20 \mu \mathrm{m}$. The rime ice condition was at $103 \mathrm{~m} / \mathrm{s}(230 \mathrm{mph})$, - $17.2{ }^{\circ} \mathrm{C}\left(1^{\circ} \mathrm{F}\right), 0.36 \mathrm{~g} / \mathrm{m}^{3}$, and $20 \mu \mathrm{m}$.

\section{Test}

The airspeed for both icing conditions was $103 \mathrm{~m} / \mathrm{s}$ (230 mph). The total temperature for glaze ice condition was $-6.7{ }^{\circ} \mathrm{C}\left(20^{\circ} \mathrm{F}\right)$ with $0.5 \mathrm{~g} / \mathrm{m}^{3}$ of LWC, and an MVD of $20 \mu \mathrm{m}$. The rime ice condition was at $-20{ }^{\circ} \mathrm{C}\left(-4{ }^{\circ} \mathrm{F}\right), 0.38$ $\mathrm{g} / \mathrm{m}^{3}$, and $20 \mu \mathrm{m}$.

\section{Deicer Operation}

Each deicer was fired at specified intervals during a continuous spray event. Spray times ranged from 10 to 30 minutes depending on cycling intervals. During the 1990 test, three cycling times were used: 60,180 , and 300 seconds. Many more cycling times were used during the 1991 test to study effects of short cycling times on the system performance. Cycling times used during the 1991 test were $15,30,60,90,120$, 180 , and 240 seconds.

During the 1991 test, the two deicers were operated at various pressure /energy settings to study their effects on deicer performance. Two operating pressures, 4482 and $5516 \mathrm{kPa}(650$ and $800 \mathrm{psi}$, were used for the PIIP system, and three capacitor bank energy settings that resulted in peak electrical currents of 3300,3550 , and 4160 amperes were used for the EEDS. Results with $5516 \mathrm{kPa}$ for the PIIP system and 3550 amperes for the EEDS will be presented in this paper.

\section{Experimental Procedure}

The standard routine for each run involved starting the icing spray when the IRT was at the specified test condition. At the end of the spray and before the final deicer cycle, the tunnel speed was brought down to idle and test personnel went inside the test section to measure pre-fire ice thickness at various spanwise locations on the leading edge and the lower surface (pressure side) adjacent to the leading edge. The upper surface (suction side) was normally clear, but measurements were made there if noticeable residual ice was present.

Once these measurements were made, and any visual data recorded, the tunnel was brought up to operating speed for a final shed event. The tunnel was then stopped, and a final set of postfire residual ice measurements were taken. Spanwise locations of ice, known as cap ice, left along the leading edge tip were also documented. The model was then cleaned off for the next test.

\section{Results and Discussions}

In this section, selected results from both 1990 and 1991 tests are presented. Results showed that cyclic deicing operations with cycling intervals above 1 minute normally left no residual ice at the leading edge. Therefore, the surface was cleaned every time a deicer was fired and new ice accreted until the next firing. Cycling times above one minute allowed fairly thick ice buildups between firings. These thicker ice buildups may not be realistic when considering effects on wing aerodynamics. For example, an average ice buildup between firings for the rime ice condition was $3.2 \mathrm{~mm}$ for a cyclic deicing operation with a cycling time of 180 seconds during the 1990 test. For this reason, results presented herein are limited to residual ice thicknesses for cycling times equal to or less than 1 minute.

All residual ice thickness measurements were point measurements using the dial gage described earlier. Measurements resulted in conservative readings because the bottom plate of the dial gage was placed against high points of the iced surface as illustrated in Fig. 5. 
Each test point was repeated at least twice to document repeatability of the data. Plots presented in following sections were generated with the highest residual ice thickness values among repeat points.

\section{Residual Ice Pattern}

Figures 6-9 show typical residual ice on the airfoil surface before and after deicers were fired. Figure 7 shows a clean leading edge and a pressure side with residual ice. This represents a typical residual ice pattern when a deicer successfully cleaned the leading edge. Figure 9 shows a typical residual ice pattern when the leading edge was not fully cleaned. This pattern was more prominent with short cycling times such as 15 and 30 seconds during the 1991 test. Both clean spots and spots with residual ice are seen on the surface, and it was observed during the tests that locations of these spots varied. The observation suggests that roughness associated with the second kind of residual ice pattern may have quite different effects on wing aerodynamics than distributed roughness.

\section{Results from 1990 Test}

Residual ice thickness was measured at the leading edge and at the lower surface (pressure side) in the deicer active coverage region. Most times, no residual ice was present on the upper surface (suction side), therefore, only results at the leading edge and lower surface are presented. As mentioned earlier, only results with one minute cycling time are presented among the three cycling times tested. Residual ice data was obtained for the DNE EEDS at 3 and 5 minute cycling times. But the unique deicer segment design and its firing sequences did not allow operation at the 1 minute cycling time. Therefore no data for the DNE EEDS is included in this paper.

The characteristics of the residual ice at the mid-span location were used to represent ice removal capability. All the EIDI systems had coils at the midspan and the PIIP and STP systems did not have spanwise variations of performance due to their design configurations. Also, ice accretion was believed to be most representative for the given cloud conditions at the midspan where cloud uniformity was considered to be best. For these reasons, the results are presented for the measurements at the mid-span.

Figure 10 shows residual ice thickness measured at the leading edge for both glaze and rime ice conditions. Residual ice thickness measured just prior to the last firing is referred to as 'Pre-Firing' and thickness measured just after the last firing is referred to as 'Post-Firing'. 'Initial Ice Buildup' represents an ice thickness expected to accrete on a clean surface for one minute. Initial ice buildup thicknesses for glaze and rime ice were determined by averaging pre-firing thicknesses of the BFG PIIP and Electroimpact EDS systems. Both systems cleaned the surface at every firing, therefore, their pre-firing thicknesses reflected realistic ice accretions for one minute. Since each deicer was cycled during the whole spray, the pre-firing thickness included any residual ice from previous firings and subsequent ice buildup just prior to the last firing.

Most systems except the BFG STP system showed pre-firing thickness values close to the initial ice buildup. For these systems, the results indicate that deicers cleaned the ice accreted for one minute and the pre-firing thickness reflects only a subsequent buildup for the next one minute. The results also indicate that the leading edge would have a minimum ice buildup of $1.27 \mathrm{~mm}$ (0.05 in) thick for glaze ice or $1.52 \mathrm{~mm}$ (0.06 in) thick for rime ice at least one point during a one minute cycling operation for these icing conditions.

Figure 11 shows residual ice thicknesses at the pressure surface. 
Unlike at the leading edge, none of the systems cleared ice on the lower surface completely during deicing operations. The BFG PIIP and Electroimpact EDS systems left the least amount of ice, typically less than $0.25 \mathrm{~mm}(0.01 \mathrm{in})$ thick, therefore initial ice buildup thicknesses were again determined by averaging pre-firing thicknesses of the BFG PIIP and Electroimpact EDS systems. Most systems had pre-firing thicknesses higher than post-firing thicknesses with both being higher than the initial ice buildup value. The results indicate that, for each system, the surface was never cleaned completely throughout the cyclic deicing operation, and it is most likely that the lowest roughness level corresponded to the post-firing thickness. One thing to note here is that initial ice buildups for both glaze and rime ice were about $0.75 \mathrm{~mm}$ (0.03 in) which is much thinner than the initial ice buildups at the leading edge. All deicers tested were basically inertia based systems, which means they require some mass of ice to generate a expelling force sufficient to debond the ice from the surface. Based on the deterioration of ice removal capability compared to the leading edge results, it appears that initial ice buildups at the lower surface did not have enough mass and systems were not as effective in removing ice here.

\section{Results from 1991 Test}

During the 1991 test, the systems were tested for much shorter cycling times than during the 1990 test to study effects of short cycling times on the system performance. Results with three cycling times $(15,30$, and 60 seconds) are presented. Residual ice thickness was measured at the leading edge and at the lower surface (pressure side). The results are presented for the measurements at the mid-span for the same reasons as for the 1990 test.

Figure 12 shows residual ice thicknesses with three cycling times for the BFG PIIP system. The results clearly show an effect of the mass of pre-fire ice on the ice removal capability of the system. By changing the cycling time under the same icing condition, the mass of pre-fire ice on the surface can be changed. For the cycling times of 30 and 60 seconds with pre-firing thicknesses above $1 \mathrm{~mm}$, the surface was clean after the deicer was activated. For the cycling time of 15 seconds when a pre-firing thickness was in the order of $0.76 \mathrm{~mm}$ (0.03 in), the deicer left residual ice. The results suggest that the leading edge roughness would be less severe with the 15 second cycling interval operation than with the other two cycling times, although there would be residual ice at all times during the 15 second cyclic deicing session.

Figure 13 shows the results for the BFG PIIP system at the lower surface. Again the results show the effect of the mass of ice on the effectiveness of the deicer. For the glaze ice condition, the difference between the pre- and postfiring thickness became smaller as the cycling time became shorter. The results indicate that the ice removal effectiveness deteriorated as the ice mass to remove became smaller. The results for the rime ice condition show basically the same trend.

Figures 14 and 15 show the results for the BFG EEDS. With this system, the effect of the mass of ice is not as clearly shown as for the PIIP system. The results at the leading edge show that the EEDS never removed the ice down to the bare surface; some post-fire residual ice was always present except for the 1 minute cycling time for the rime ice condition. The pre- and post-firing thicknesses became smaller as the cycling time became shorter. At the lower surface, a decrease in effectiveness with the cycling time is more prominent for glaze ice condition, but not so prominent for the rime ice condition. 
Although both PIIP and EEDS are inertia based systems, their design concepts and operating process were different. Therefore, results need to be considered as configuration specific.

\section{Conclusions}

Thicknesses of residual ice during cyclic deicing events with cycling times equal to and less than 1 minute have been presented. The results presented in this paper reflect residual ice information for the specific test models. Each deicer was optimized for this specific application, therefore, the performance of a deicer can be different for other applications due to different design considerations.

It is obvious that leading edge contamination by residual ice will have an effect on lift and drag of a wing. However, no aerodynamic studies have been made with actual residual ice to investigate its effects on wing aerodynamics. Residual ice patterns observed during the tests suggest that uniformly distributed roughness applied on the leading edge may not be appropriate to describe characteristics of roughness associated with residual ice. Therefore more studies need to be made to address the relation between the residual ice roughness and the uniformly distributed roughness. Quantification of the extent of residual ice is one area needed to better understand the relation.

It was observed that all deicing systems tested required a certain amount of ice buildup on the surface for effective ice removal performance. Results indicated that the surface was cleaned only when the ice accretion reached this critical mass and below this critical mass the effectiveness in ice removal was independent of the frequency of cycles. This implies that there will be a contamination by residual ice and subsequent ice buildups at all times during a cyclic deicing event if a deicer were cycled too fast. For this case, the most severe roughness between cycles would be equal to the thickness corresponding to the critical mass plus any subsequent ice buildup. Therefore, it is very important to know the minimum thickness a deicer can remove for effective ice removal.

\section{$\underline{\text { Reference }}$}

1. Brumby, R.E., "The Effect of Wing Ice Contamination on Essential Flight Characteristics," AGARD Conference Proceedings on Effects of Adverse weather on Aerodynamics, pp. 2-1 to 2-4, AGARD-CP-496, December, 1991.

2. Lynch, F.T., Valarezo, W.O., and McGhee, R.J., "The Adverse Aerodynamic Impact of Very Small Leading-Edge Ice (Roughness) Buildups on Wings and Tails," AGARD Conference Proceedings on Effects of Adverse Weather on Aerodynamics, pp. $12-1$ to $12-8$, AGARD-CP-496, December, 1991.

3. Oolbekkink, B. and Volkers, D.F., "Aerodynamic Effects of Distributed Roughness on a NACA $63_{2}-015$ Airfoil," AIAA Paper 91-0443, Jan., 1991.

4. Kind, R.J. and Lawrysyn, M.A., "Effects of Frost on Wing Aerodynamics and Take-Off Performance," AGARD Conference Proceedings on Effects of Adverse Weather on Aerodynamics, pp. 8-1 to 8-11, AGARD-CP-496, December, 1991.

5. van Hengst, J. and Boer, J.N, "The Effect of Hoar-Frosted Wings on the Fokker $50 \quad$ Take-Off Characteristics," AGARD Conference Proceedings on Effects of Adverse weather on Aerodynamics, pp. 13-1 to 13-9, AGARD-CP-496, December, 1991.

6. Bond, T.H., Shin, J., and Mesander, G., "Advanced Ice Protection 
Systems Test in the NASA Lewis Icing Research Tunnel," Presented at the 47th American Helicopter Society Annual Forum and Technology Display, Phoenix, AZ, May, 1991, (also NASA TM 103757).
7. Bond, T.H. and Shin, J., "Results of Low Power Deicer Tests on a Swept Inlet Component in the Lewis Icing Research Tunnel," AIAA Paper 930032, Jan., 1993.

Table 1. Participants of the 1990 Low Power Ice Protection Systems Test

\begin{tabular}{|l|ll|}
\hline Company & System & \\
\hline BFGoodrich De-Icing Systems & Pneumatic Impulse Ice Protection & (PIIP) \\
BFGoodrich De-Icing Systems & Small Tube Pneumatic & (STP) \\
Rohr Industries, Inc. & Electro-Impulse De-Icing & (EIDI) \\
Electroimpact, Inc. & Eddy Current Deicing Strip & (EDS) \\
BFGoodrich De-Icing Systems & Electro-Mechanical System & (EMS) \\
Advance Concepts De-Icing Company & Electro-Impulse De-Icing & (EIDI) \\
Garrett Canada & Electro-Impulse De-Icing & (EIDI) \\
Dataproducts New England, Inc. & Electro-Expulsive De-Icing System & (EEDS) \\
\hline
\end{tabular}

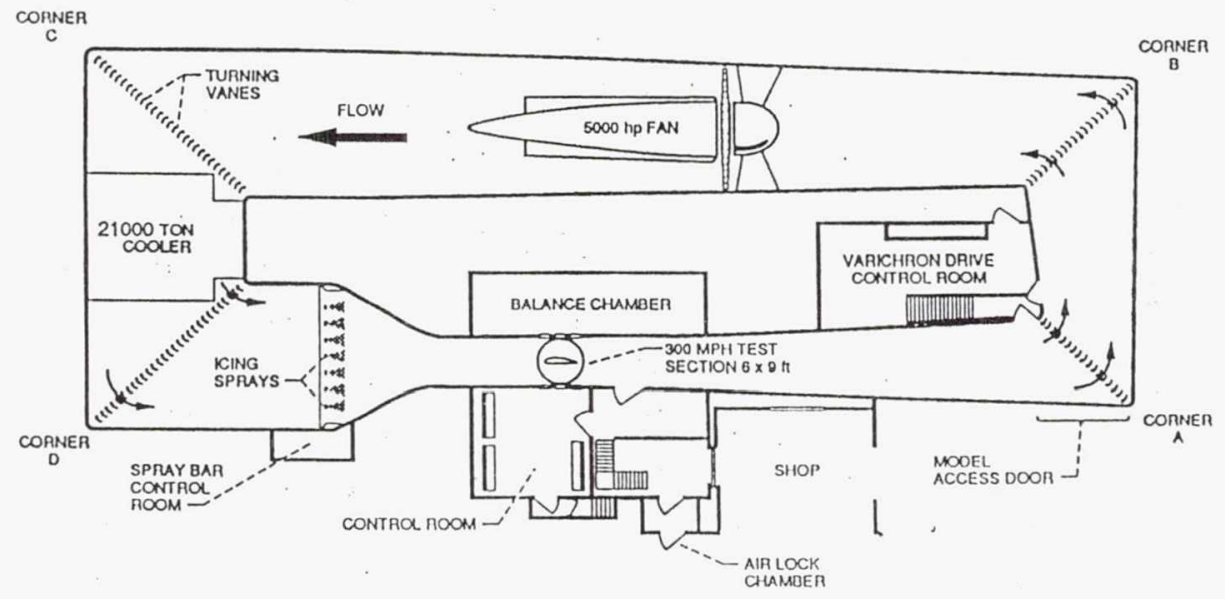

Figure 1. Schematic View of IRT and Control Room. 


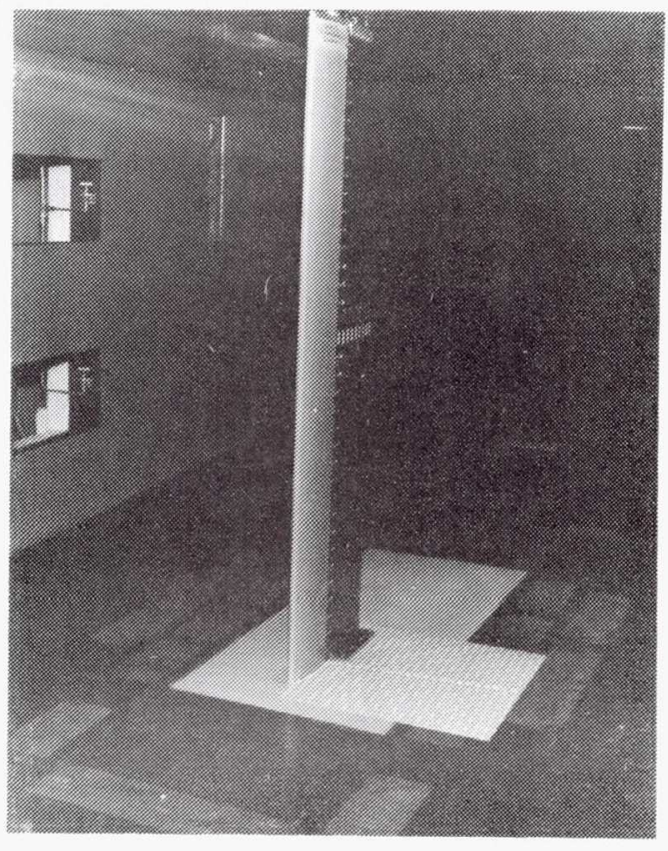

Figure 2. NACA 0012 Airfoil with Low Power Deicer in the IRT.

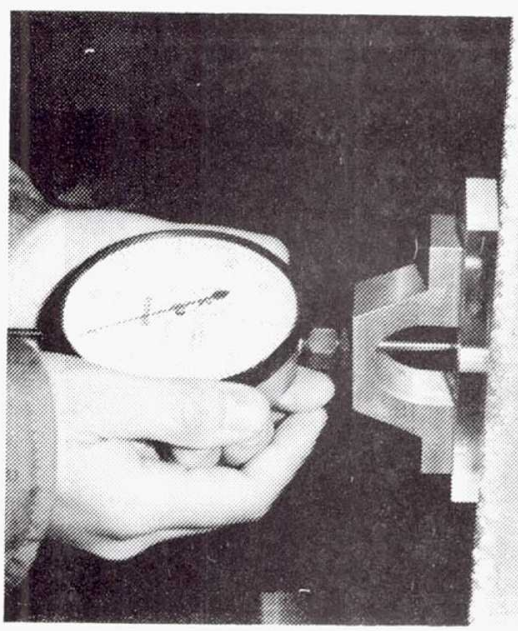

Figure 4. Dial Gage used for Ice Thickness Measurement.

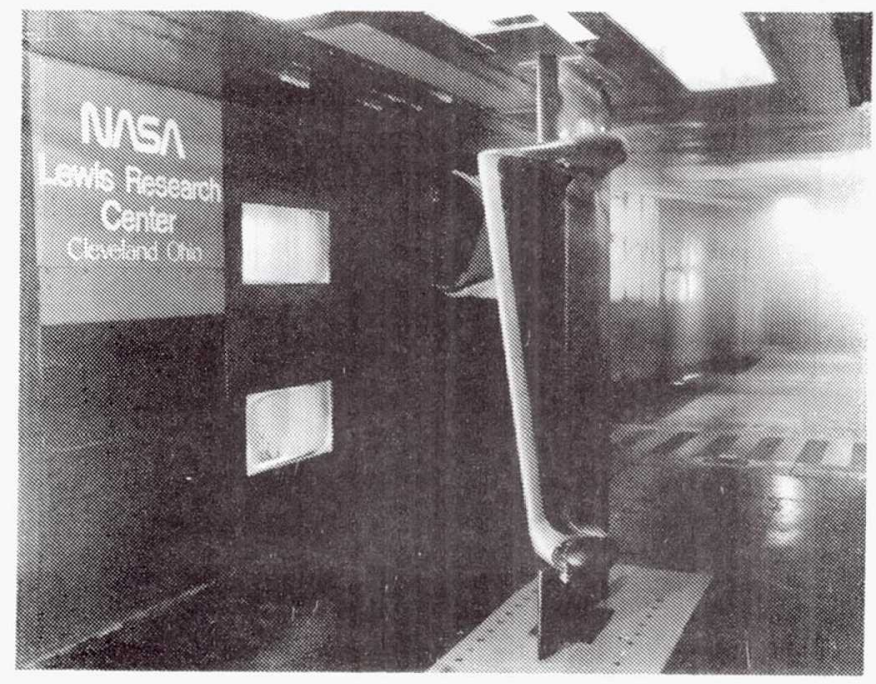

Figure 3. Swept Engine Inlet Component with Low Power Deicer in the IRT.

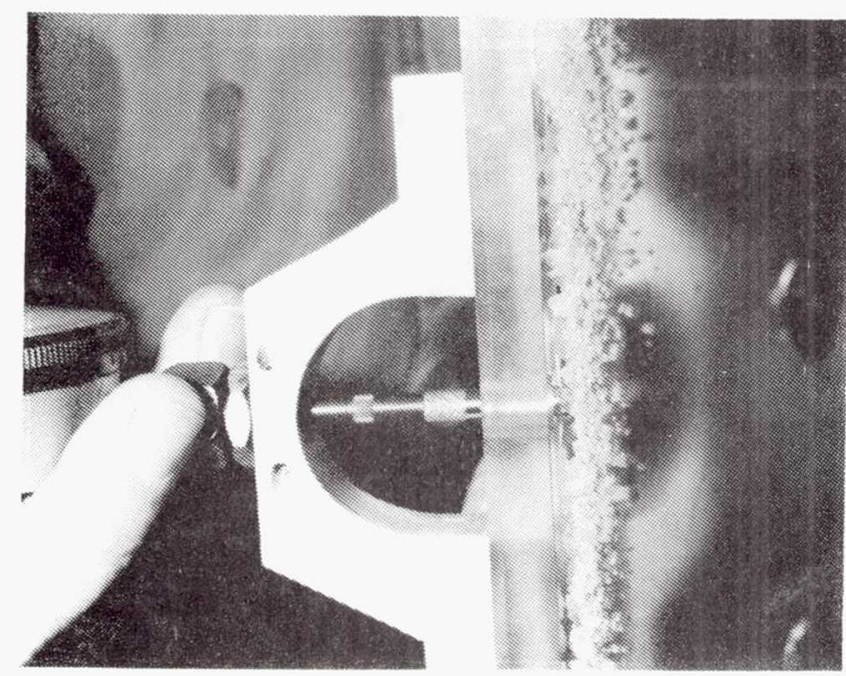

Figure 5. Residual Ice Thickness Measurement - Air Gaps under High Points. 

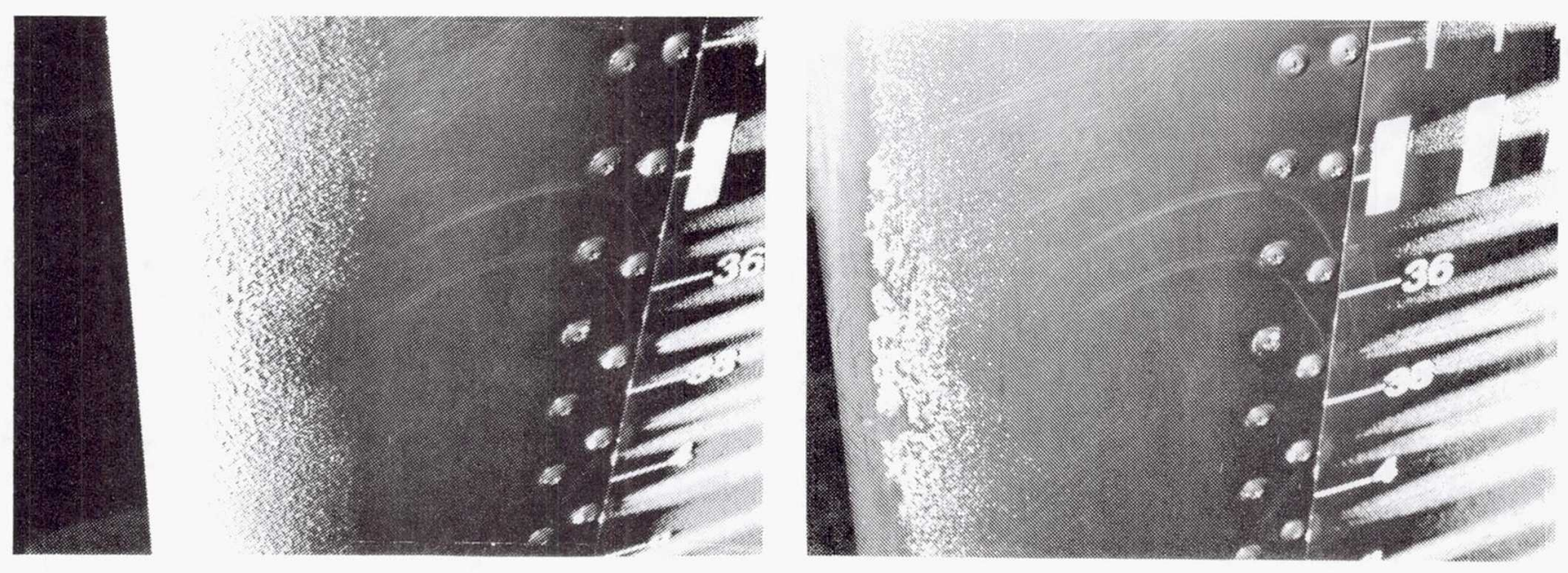

Figure 6. Residual Ice Pattern with $1 \mathrm{~min}$. Cycling Time for Rime Ice (Pre-Fire).

Figure 7. Residual Ice Pattern with 1 min. Cycling Time for Rime Ice (Post-Fire).

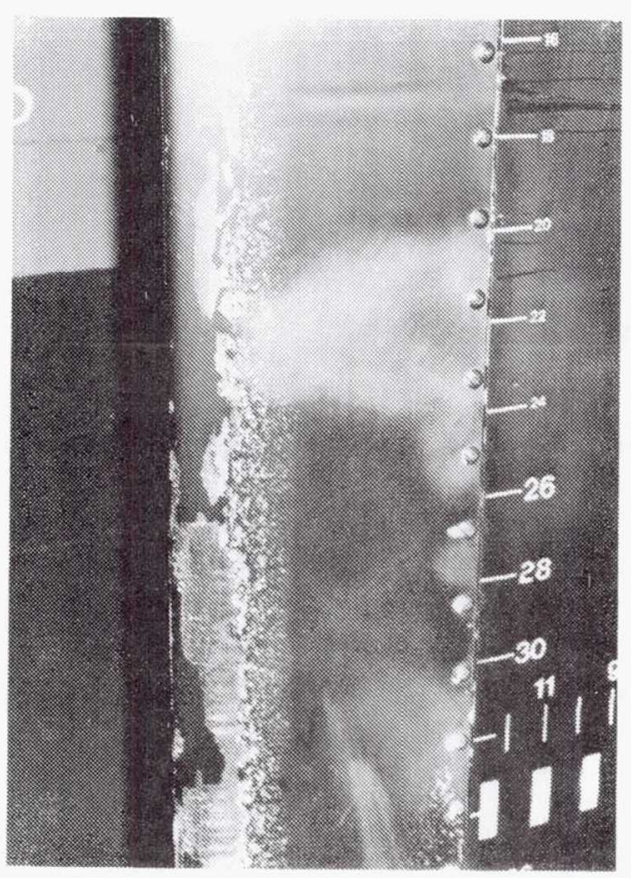

Figure 8. Residual Ice Pattern with $1 \mathrm{~min}$. Cycling Time for Glaze Ice (Pre-Fire).

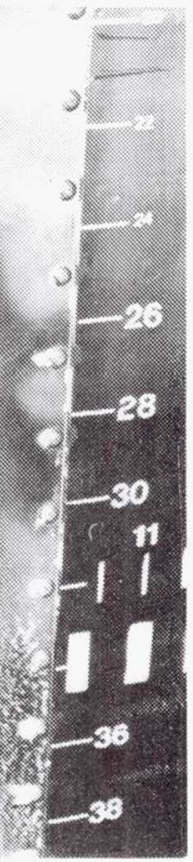

Figure 9. Residual Ice Pattern with 1 min. Cycling Time for Glaze Ice (Post-Fire). 


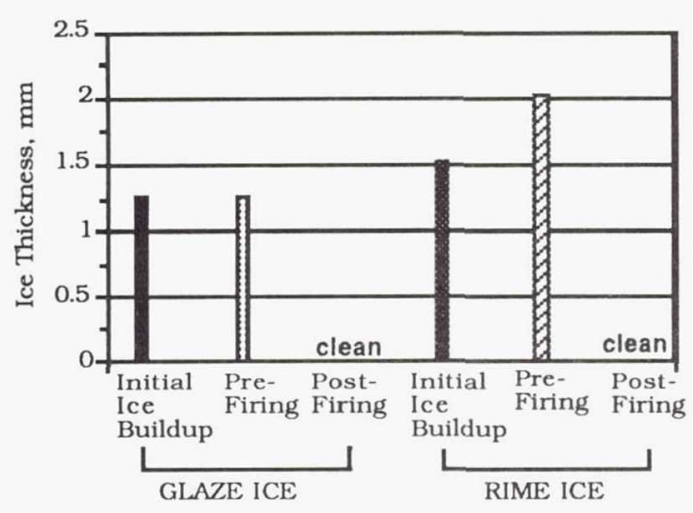

(a) BFG-PIIP

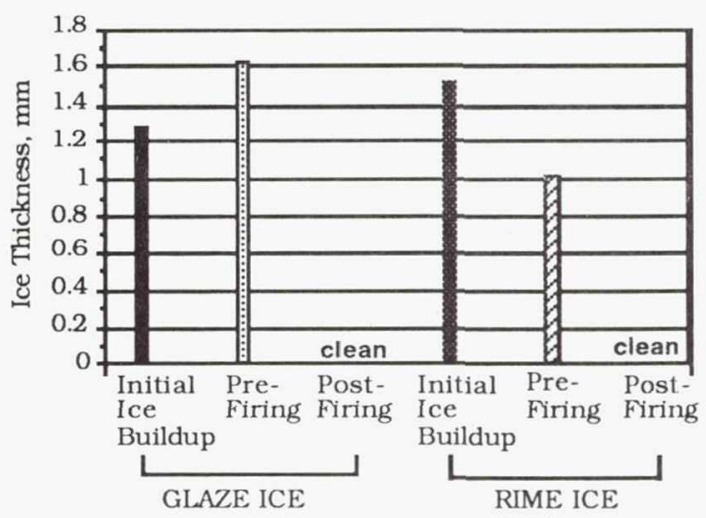

(c) Rohr-EIDI

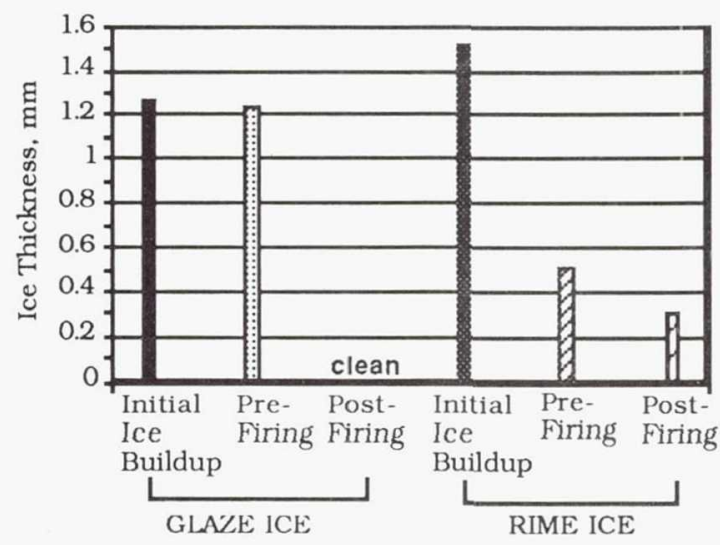

(e) BFG-EMS

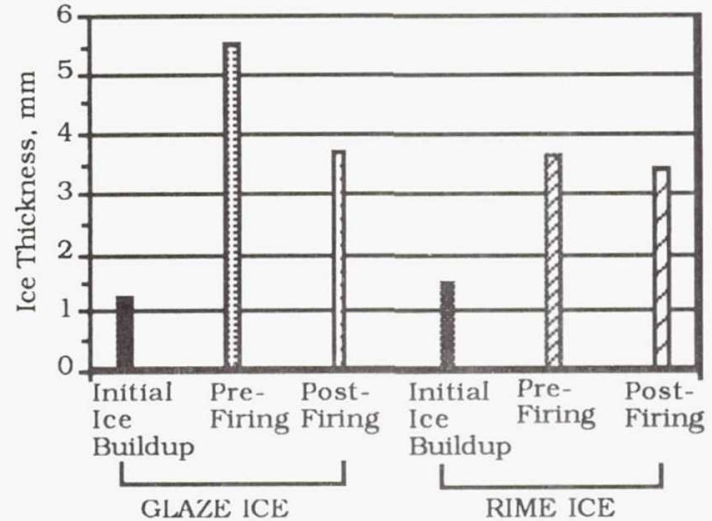

(b) BFG-STP

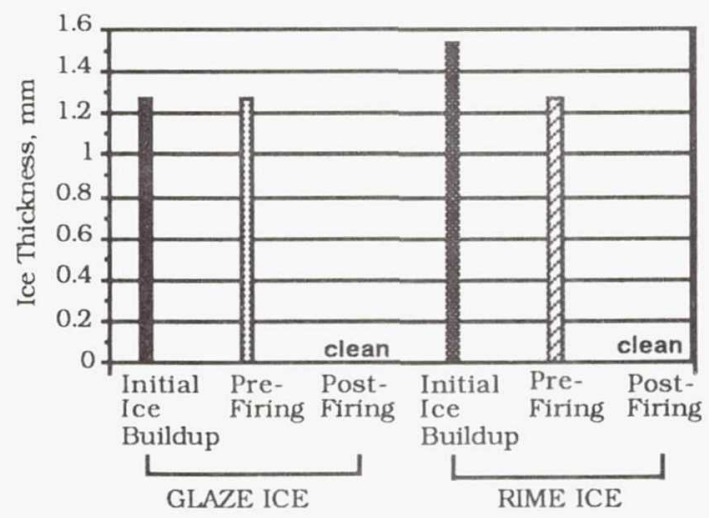

(d) EI-EDS

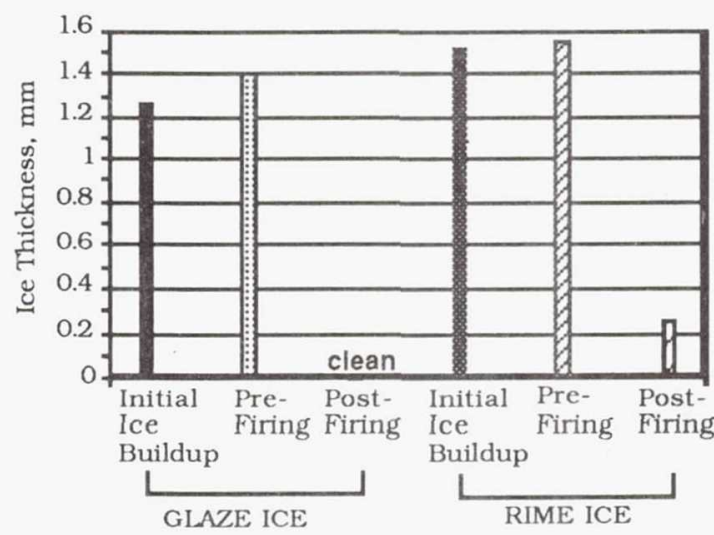

(f) ACDC-EIDI

Figure 10. Leading Edge Residual Ice Thickness (One Minute Cycling Time). 


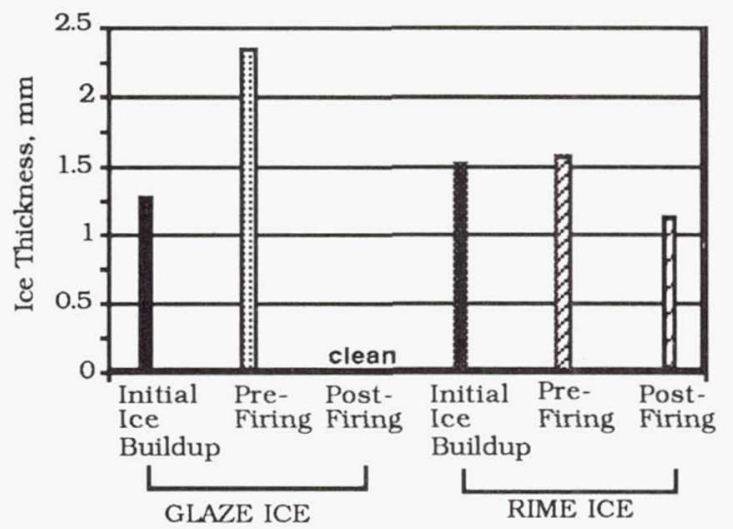

(g) Garrett-EIDI

Figure10. (Cont'd) Leading Edge Residual Ice Thickness (One Minute Cycling Time).

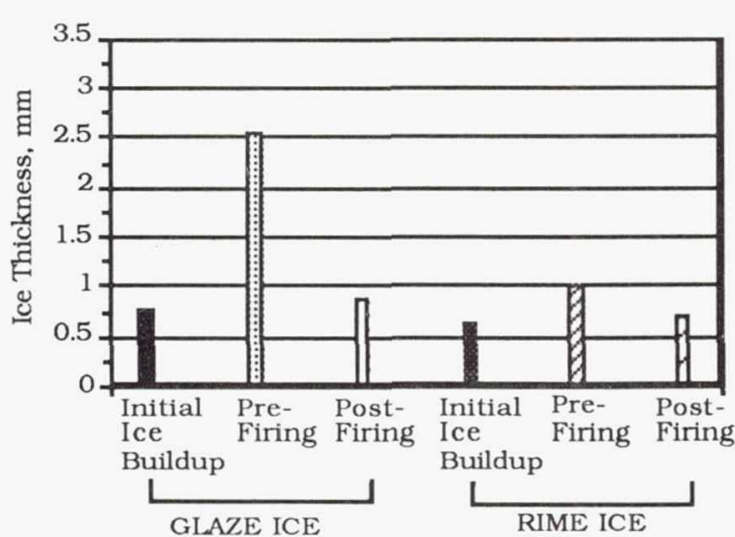

(a) BFG-PIIP

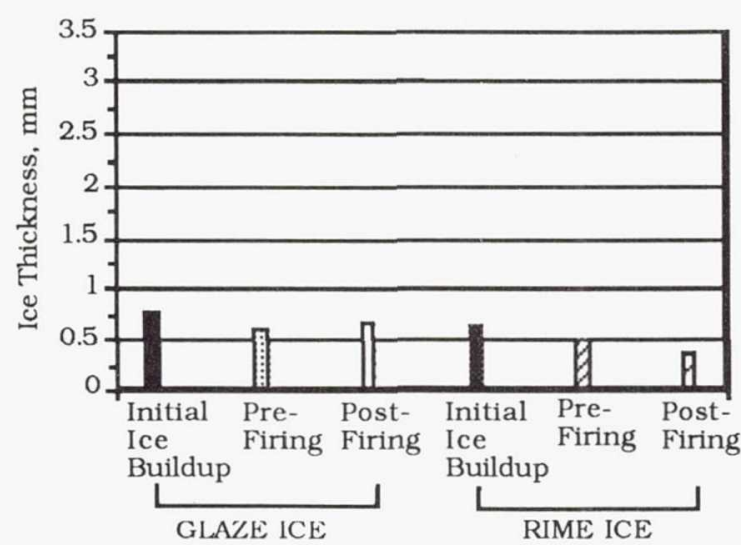

(c) Rohr-EIDI

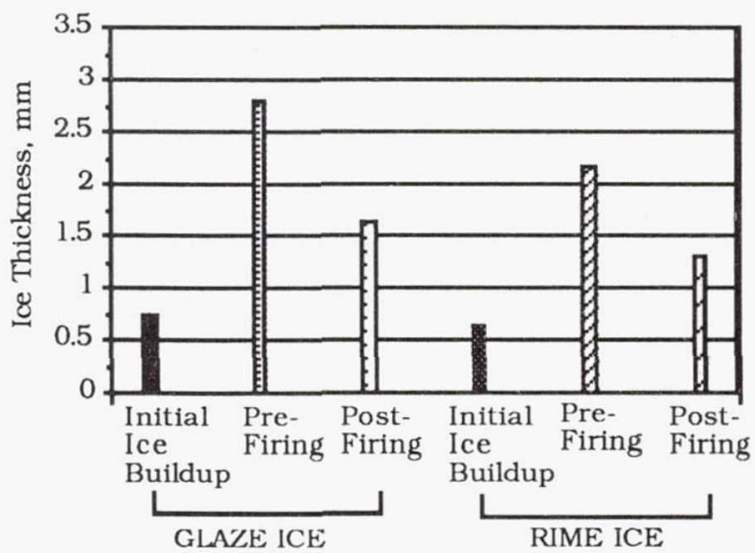

(b) BFG-STP

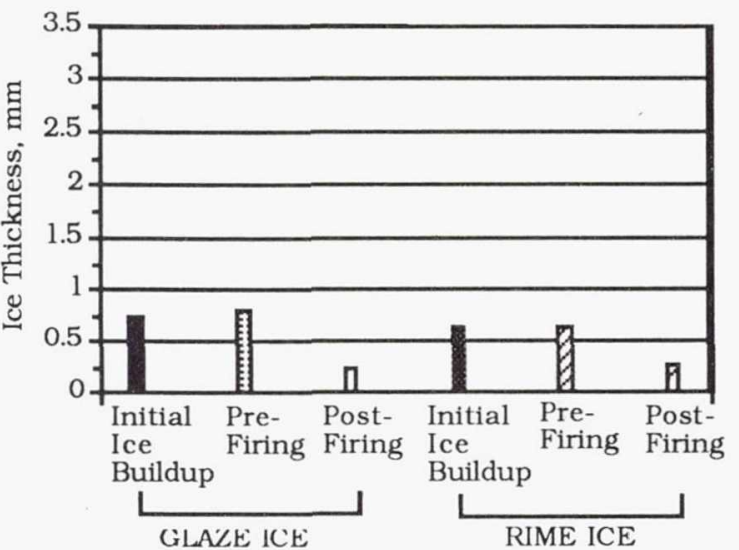

(d) EI-EDS

Figure 11. Lower Surface Residual Ice Thickness (One Minute Cycling Time). 


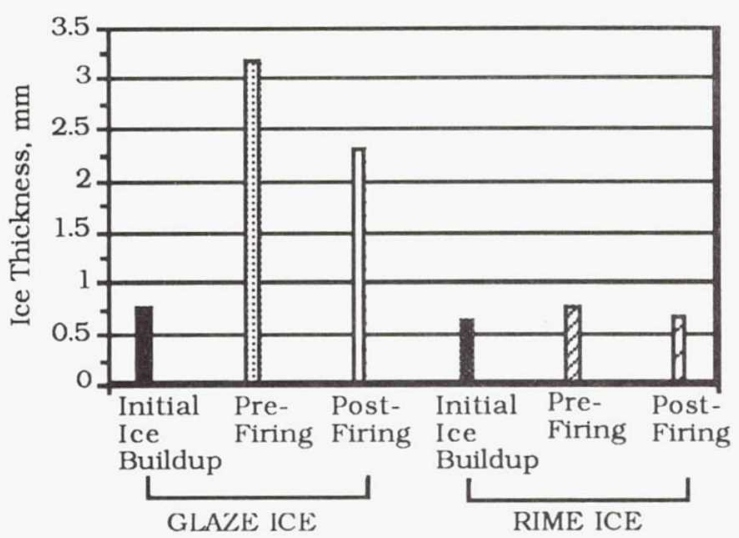

(e) BFG-EMS

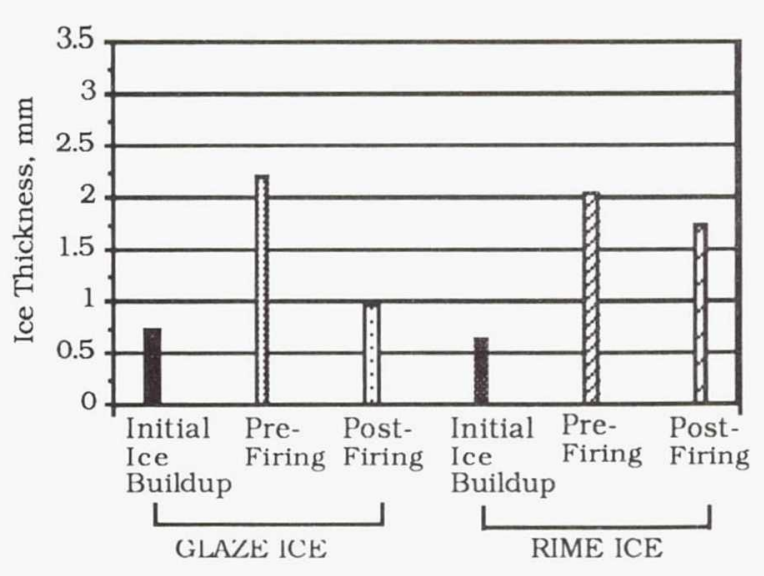

(g) Garrett-EIDI

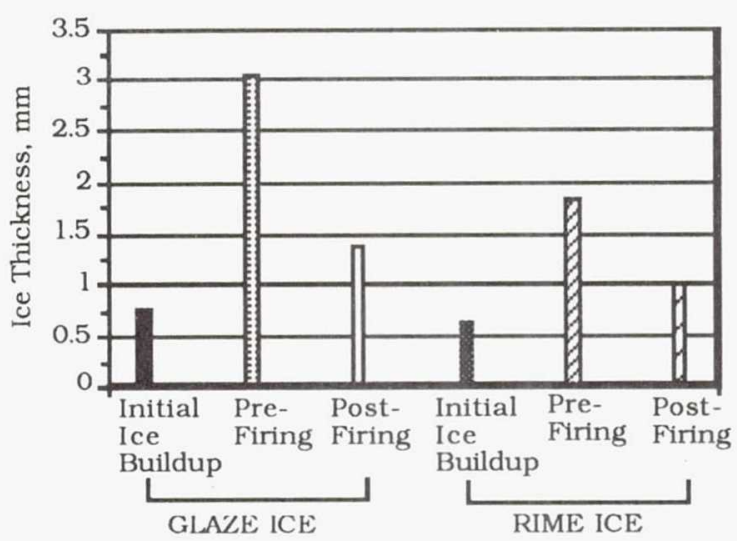

(f) ACDC-EIDI

Figure 11. (Cont'd) Lower Surface Residual Ice Thickness (One Minute Cycling Time).

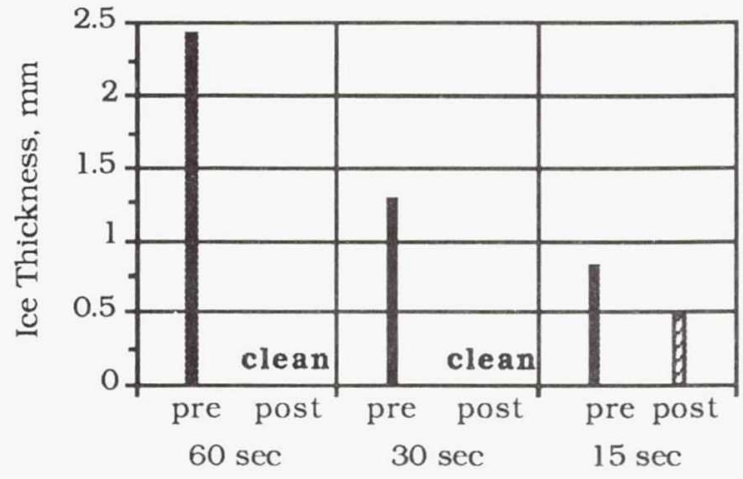

Cycling Time

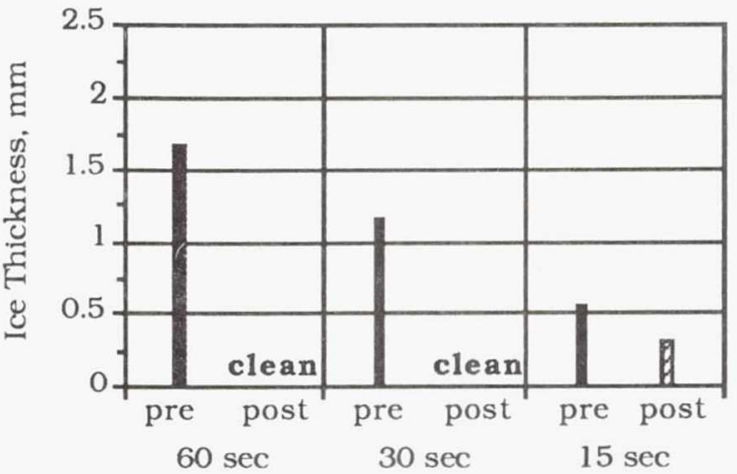

Cycling Time
(a) Total Temperature $=-6.7^{\circ} \mathrm{C}$
(b) Total Temperature $=-20{ }^{\circ} \mathrm{C}$

Figure 12. Effect of Cycling Time on Leading Edge Residual Ice Thickness (BFG-PIIP). 


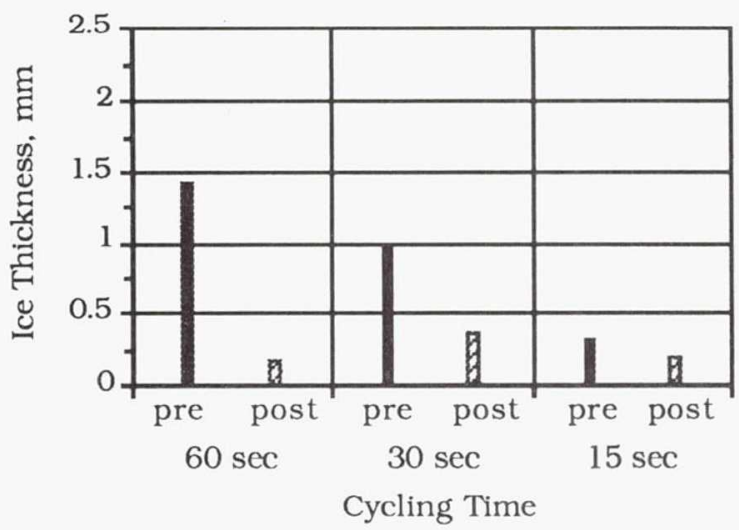

(a) Total Temperature $=-6.7^{\circ} \mathrm{C}$

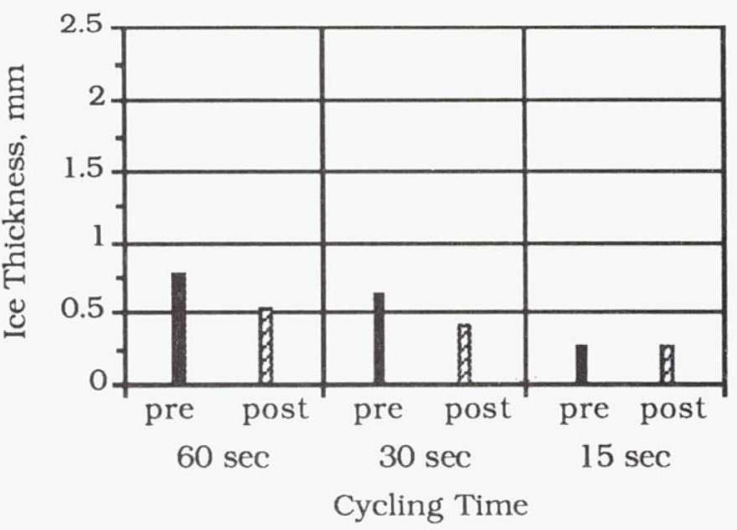

(b) Total Temperature $=-20^{\circ} \mathrm{C}$

Figure 13. Effect of Cycling Time on Lower Surface Residual Ice Thickness (BFG-PIIP).

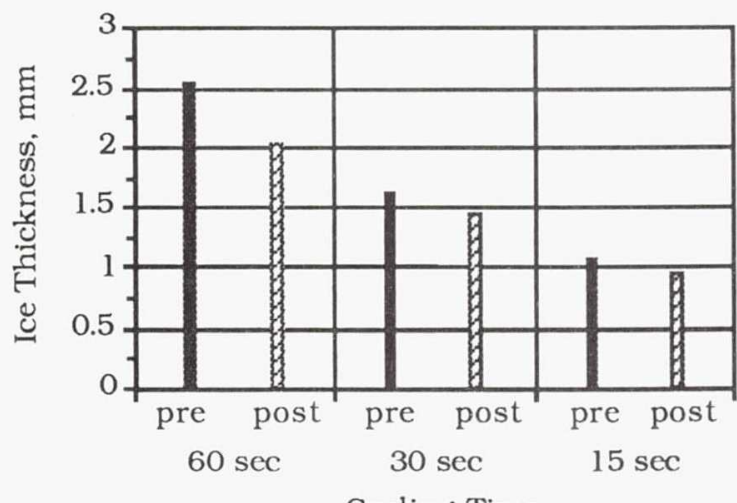

Cycling Time

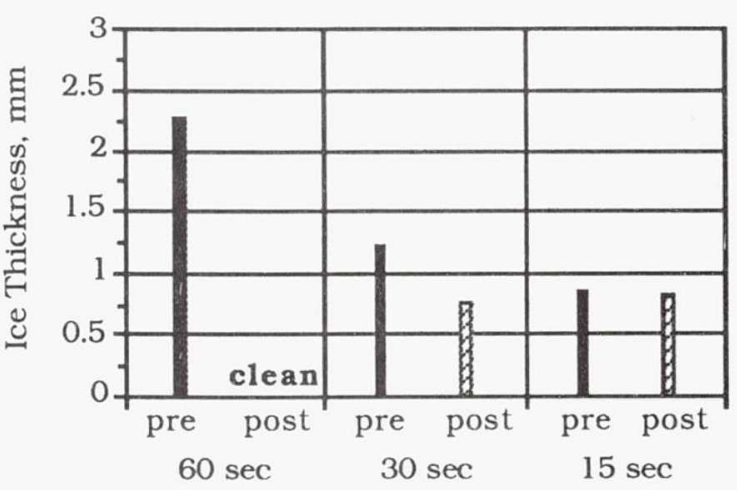

Cycling Time
(a) Total Temperature $=-6.7^{\circ} \mathrm{C}$
(b) Total Temperature $=-20{ }^{\circ} \mathrm{C}$

Figure 14. Effect of Cycling Time on Leading Edge Residual Ice Thickness (BFG-EEDS).

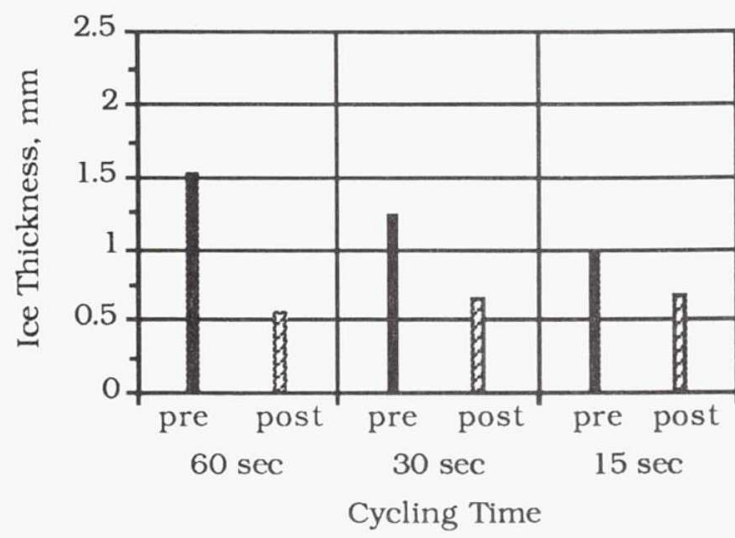

(a) Total Temperature $=-6.7^{\circ} \mathrm{C}$

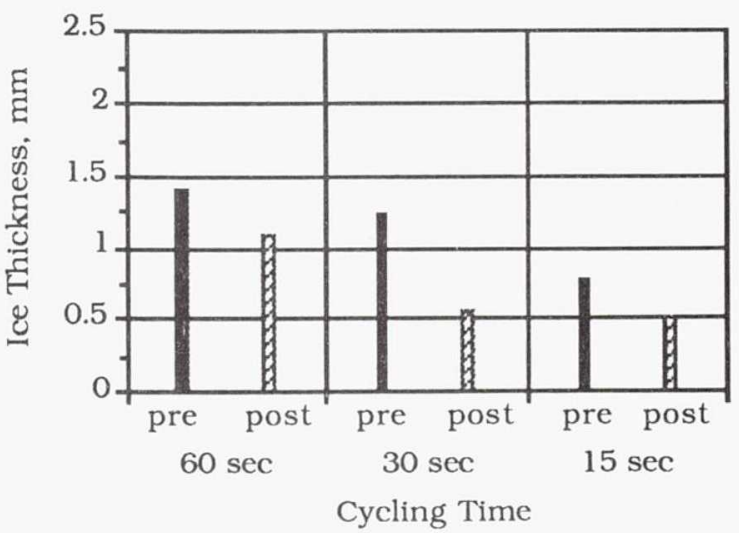

(b) Total Temperature $=-20^{\circ} \mathrm{C}$

Figure 15. Effect of Cycling Time on Lower Surface Residual Ice Thickness (BFG-EEDS). 
Public reporting burden for this collection of information is estimated to average 1 hour per response, including the time for reviewing instructions, searching existing data sources, gathering and maintaining the data needed, and completing and reviewing the collection of information. Send comments regarding this burden estimate or any other aspect of this collection of information, including suggestions for reducing this burden, to Washington Headquarters Services, Directorate for information Operations and Reports, 1215 Jefferson Davis Highway, Suite 1204, Arlington, VA 22202-4302, and to the Office of Management and Budget, Paperwork Reduction Project (0704-0188), Washington, DC 20503.

\begin{tabular}{|l|c|c|}
\hline 1. AGENCY USE ONLY (Leave blank) & $\begin{array}{c}\text { 2. REPORT DATE } \\
\text { January } 1993\end{array}$ & $\begin{array}{r}\text { 3. REPORT TYPE AND DATES COVERED } \\
\text { Technical Memorandum }\end{array}$ \\
\hline
\end{tabular}

\section{TITLE AND SUBTITLE}

Surface Roughness Due to Residual Ice in the Use of Low Power

Deicing Systems

\section{AUTHOR(S)}

Jaiwon Shin and Thomas H. Bond

\section{PERFORMING ORGANIZATION NAME(S) AND ADDRESS(ES)}

National Aeronautics and Space Administration

Lewis Research Center

Cleveland, Ohio 44135-3191

9. SPONSORING/MONITORING AGENCY NAMES(S) AND ADDRESS(ES)

National Aeronautics and Space Administration

Washington, D.C. 20546-0001
5. FUNDING NUMBERS

WU-505-68-10

8. PERFORMING ORGANIZATION REPORT NUMBER

E-7494

10. SPONSORING/MONITORING AGENCY REPORT NUMBER

NASA TM-105971

AIAA-93-0031

\section{SUPPLEMENTARY NOTES}

Prepared for the 31st Aerospace Sciences Meeting \& Exhibit sponsored by the American Institute of Aeronautics and Astronautics, Reno, Nevada, January 11-14, 1993. Jaiwon Shin and Thomas H. Bond, NASA Lewis Research Center. Responsible person, Jaiwon Shin, (216) 433-8714.

12a. DISTRIBUTION/AVAILABILITY STATEMENT 12b. DISTRIBUTION CODE

Unclassified - Unlimited

Subject Category 02

\section{ABSTRACT (Maximum 200 words)}

Thicknesses of residual ice are presented to provide information on surface contamination and associated roughness during deicing events. Data was obtained from low power ice protection systems tests conducted in the Icing Research Tunnel at NASA Lewis Research Center (LeRC) with nine different deicing systems. Results show that roughness associated with residual ice is not characterized by uniformly distributed roughness. Results also show that deicing systems require a critical mass of ice to generate a sufficient expelling force to remove the ice.

\section{SUBJECT TERMS}

Surface roughness; Residual ice; Deicing systems

\section{SECURITY CLASSIFICATION OF REPORT}

Unclassified
18. SECURITY CLASSIFICATION OF THIS PAGE Unclassified
19. SECURITY CLASSIFICATION OF ABSTRACT Unclassified 
National Aeronautics and Space Administration

Lewis Research Center

Cleveland, Ohio 44135

Official Business

Penalty for Private Use $\mathbf{\$ 3 0 0}$
FOURTH CLASS MAIL

ADDRESS CORRECTION REQUESTED

\section{疍}

Postage and Fees Paid National Aeronautics and Space Administration NASA 451 